\title{
Medical, psychological, and social factors associated with back abnormalities and self reported back pain: a cross sectional study of male employees in a Swedish pulp and paper industry
}

\author{
N-E ÅTTRAND \\ From the Department of Community Health Sciences, Lund University, Malmö, Sweden
}

ABSTRACT A medical, psychological, and sociological study of 391 male employees in a Swedish pulp and paper industry was performed in 1961. Factors associated with back pain and back abnormality were investigated. Univariate analyses showed associations of back pain with occupational status, low education, duration of employment, low performance on cognitive tests, and neuroticism. Back abnormalities evaluated on the basis of physical examination showed in principle the same associations but the strength as well as the significances were stronger. Multiple logistic regression analyses using data for manual workers showed that neuroticism and duration of employment were directly associated with back pain. The same two variables and low performance on one of the psychological tests were directly associated with back abnormalities. Age showed no direct association with back pain or back abnormalities. Strong associations between back pain and back abnormalities with both perceived health and general working capacity and the doctor's evaluation in the same areas were demonstrated.

Back pain is a common complaint, some $50-80 \%$ of investigated populations reporting it at some time during their life. ${ }^{1-5}$ The prevalence of back pain, defined as continuous or frequently recurring, or both, is reported to be $18-31 \%$ among men and women aged $18-65 .^{5-7}$

The aetiology of back pain is by no means fully known but the following work related factors have been described as aetiological, triggering, or aggravating: heavy physical work, ${ }^{589}$ lifting, ${ }^{510} 11$ work in stooping postures, ${ }^{10}$ twisting of the back, ${ }^{8}$ prolonged standing or prolonged sedentary work, ${ }^{12}$ and vibration. ${ }^{11}$ Associations between back pain and low intelligence, ${ }^{13}$ alcohol abuse,,${ }^{14}$ and social problems ${ }^{15}$ have also been reported.

In Sweden $13 \%$ of early retirements with disability pensions in 1976 were caused largely by back complaints. ${ }^{16}$ Faxén reported in 1959 that in one Swedish community $15 \%$ of all sick leave days among men aged 16-67 was attributable to back pain ${ }^{17}$ whereas, according to Svensson, 40-47 year old men with back pain had in all $70 \%$ more sick leave days (all diag-

Accepted 8 July 1986 noses) than men of corresponding age without back trouble. $^{5}$

For occupational health practitioners the relation of back pain to the working environment is of special interest. And since neuroticism has been shown to be a common component of back pain among patients with back pain chosen for rehabilitation ${ }^{18-20}$ and in a community population, ${ }^{6}$ the contribution of neuroticism to back pain suffered in a working population is of interest.

Existing publications give inadequate guidance regarding the causes and nature of back disorders, perceived by the employee as back pain, or registered by the occupational physician as back abnormalities.

The present study was designed to answer the following questions:

(1) How frequent are back pain and back abnormalities in the male working population under study?

(2) Are perceived back pain and documented back abnormalities among certain groups of individuals related to age, sociodemographic, and psychological factors; social contacts; work environment factors; and with special reference to heavy work and neuroticism?

(3) Are back pain sufferers and subjects with back 
Table 1 Participation rates at four work sites

\begin{tabular}{lcccc}
\hline Work site & No of employees & Invited & Non-participants & Participants \\
\hline Mill 1 & 700 & 146 & $29(19 \cdot 9 \%)$ & 117 \\
Mill 2 & 400 & 80 & $6(7 \cdot 5 \%)$ & 74 \\
Mill 3 & 1000 & 188 & $36(19 \cdot 1 \%)$ & 152 \\
Head-office & 300 & 60 & $12(20 \cdot 0 \%)$ & 48 \\
Total & 2400 & 474 & $83(17 \cdot 5 \%)$ & 391 \\
\hline
\end{tabular}

abnormalities characterised by bad health and reduced working capacity.

(4) To what extent have secondary preventive measures, in the form of transfers or other changes in working conditions, been instituted on behalf of subjects with back pain and back abnormalities?

A 22 year follow up study of these workers will be reported separately.

\section{Material and methods}

The subjects for the study were 391 male employees in the Svenska Cellulosaaktiebolaget (SCA), who were working in 1961 on any of the four sites listed in table 1. These sites are located in or close to Sundsvall, a town with 90000 inhabitants, on the Baltic in northern Sweden.

The subjects were originally selected to investigate the relation between age and health among working men. The selection procedure was arranged ad hoc to obtain four different age groups representing clerks and manual workers at the four work sites. All those men who, at the time of the examination in 1961 , were aged $35,45,55$, or 65 or as close to the respective ages as possible were chosen up to a maximum of about 100 men in each age group. The nonresponse rate was $17 \cdot 5 \%$.

$T$ tests were carried out to ensure homogeneity of age. The age groups were tested by matched groups between the worksites and no significant differences were found; the age distributions are plotted in fig 1 . Subjects born between 1893 and 1900 are called 65 year olds, 1902-1910 (55 year olds), 1912-1920 (45 year olds), and 1923-1930 (35 year olds). Manual workers comprised $74 \%$ of the 35 year olds, $71 \%$ of the 45 year olds, $76 \%$ of the 55 year olds, and $84 \%$ of the 65 year olds.

The pulp and paper industry is usually regarded as a heavy industry. The production units run mainly on continuous shift work but workers in other areas worked a daytime shift although they might also be on call; double shift work occurred only to a limited extent.

The occupations in some departments were continuously physically stressful; the work at the paper machines, however, even as early as 1961 , consisted partly in supervising the process with intermittent pèriods of physically stressful work loads. Exposures to heat, moisture, and noise and, at some places, cold and draughts were usual. Most of the employees, particularly the middle aged and older workers, had been with the company a long time.

The first examination was carried out during the spring of 1961 and from it, medical, psychological, and social information was obtained and also data such as sick leave registered by the staff office.

Individual examinations took one day. Ten subjects were invited each day and passed through the examination stations according to an individual schedule. No two schedules a day were identical.

The medical examination began with a questionnaire that was a Swedish modification of the Cornell medical index (CMI) ${ }^{2122}$ performed by Nyman and Marke. ${ }^{23}$ The medical examination also comprised a

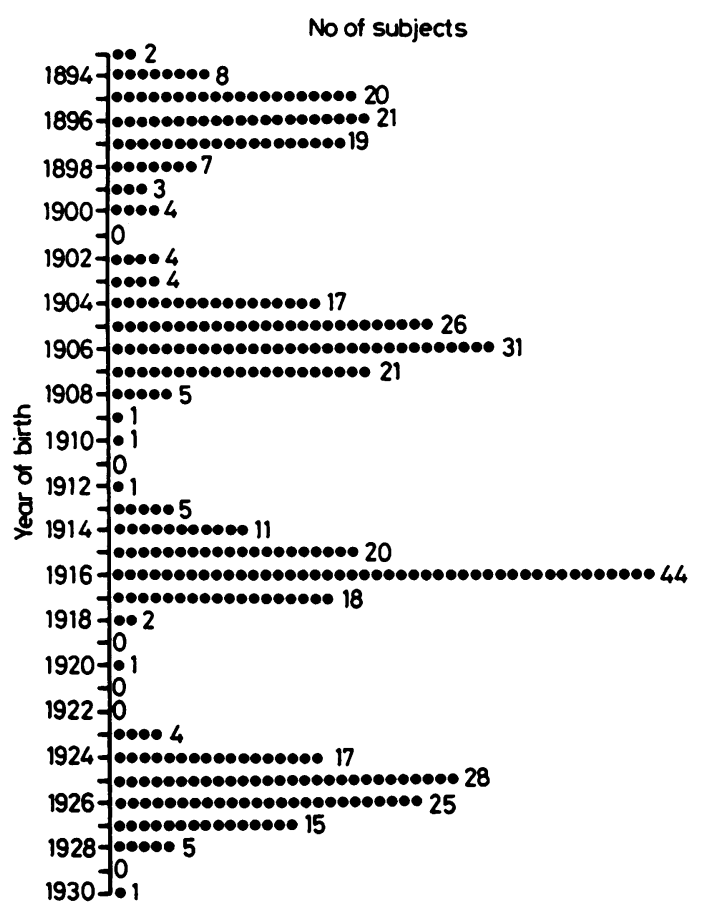

Fig 1 Age distribution in the study population. 
structured interview with questions about factors in the working environment and a non-structured interview complementing the questions in the questionnaire with regard to past and present symptoms and diseases.

A physical examination of the thoracic and lumbar spine included inspection, palpation, bending forwards and sideways, straight leg raising, dorsal flexion of the foot and big toe, and Achilles tendon reflexes. Other tests were carried out only when suggested by the history, previous knowledge of the subject, or actual findings. The examination of the back was summed up solely as "normal" or "abnormal."

Blood pressure was registered from one arm in a supine position. The diastolic pressure was registered on the disappearance of sounds. No specification regarding preceeding rest time is available. Tests for urinary protein and glucose were performed by the assistant nurse. Blood for the analysis of cholesterol was acquired in the morning before the intake of food, and the analyses were carried out at the local hospital by methods current at the time.

Marke-Nyman has constructed a scale of neuroticism on the basis of 32 questions from the Swedish modification of CMI. ${ }^{24}$ This scale was used in the analyses and is referred to below as the "MarkeNyman scale of neuroticism." The reliability of this scale is reported as $\mathbf{0 . 8 8}$ for men and the $\mathrm{DP}_{\mathbf{k}}$ (discriminating power) was at least 0.60 for 27 of the 32 questions in the scale.

The examination was carried out close to the subject's work site by the three permanent staff doctors of each work site with the help of permanent nurses. Each doctor worked full time on the project for about three weeks. One doctor had a coordinating role, functioning as an instructor to the others concerning examination methods and evaluations. No interobserver studies were performed at the time. The doctors had access to the completed questionnaire while conducting the interview and carrying out the physical examination.

The sociological instrument for examination comprised questionnaires on school and training, working conditions, family relations, housing conditions, house keeping, social contacts, leisure activities, financial state, health, and, for the oldest age group, a form evincing attitudes towards retirement. All the questionnaires were constructed by Marke (personal communication) and the questions have been used in earlier examinations. The sociological examination was carried out by three sociologists, one of whom acted as a coordinator.

The psychological examination, consisting of eight psychological tests, was conducted by one psychologist.

The following three tests are used in this study.
Synonyms-In Sweden called "SRB:1," a verbal test with a reported reliability of $0.95 .^{25}$

Instruction test-A test that measures "general intelligence." This test has earlier been used by the Swedish Institute for Military Psychology. Reliability is reported to be $0 \cdot 82 .^{26}$

Arithmetic-This test measures arithmetic skills and is constructed by the former Swedish Council for Personnel Administration. Reliability has been reported to be $0 \cdot 90-0 \cdot 92 .^{26}$

The central variables for this study were:

(1) Yes or no answers to the question: "Do you often have lumbago or pain in your back?" in this report called back pain.

(2) The summing up of the symptoms and signs elicited during the examination of the back, resulting in the classification of the back as normal or abnormal.

The classification of subjects as manual workers or clerks was carried out on the basis of reported membership of the respective trade unions. Manual workers are workers belonging to the Swedish Federation of Trade Unions (LO); foremen are organised in a separate trade union (SALF). Clerks, engineers, and

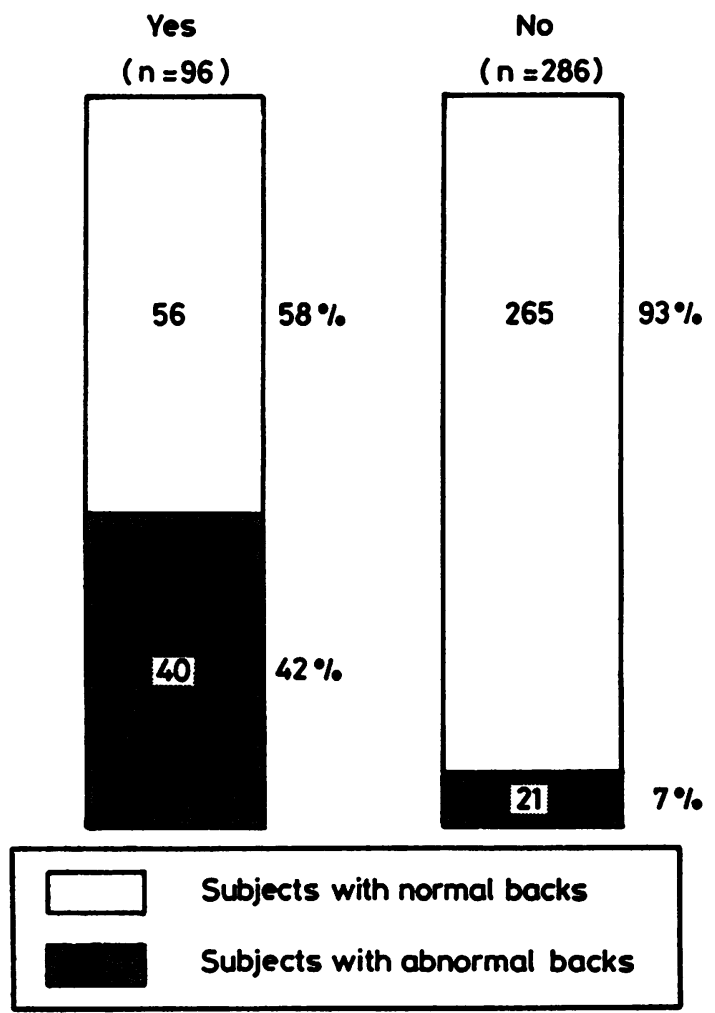

Fig 2 Answers to question: Do you often have lumbago or pain in your back? 
Table 2 Prevalence of reported back pain by sociodemographic and psychological variables

\begin{tabular}{|c|c|c|c|c|c|}
\hline & \multicolumn{2}{|c|}{ Total } & \multirow{2}{*}{$\begin{array}{l}\text { Back pain } \\
\text { No }\end{array}$} & \multirow{2}{*}{$\begin{array}{l}\text { Prevalence } \\
\%\end{array}$} & \multirow[b]{2}{*}{$p$} \\
\hline & No & $\%$ & & & \\
\hline \multicolumn{6}{|l|}{ Age group: } \\
\hline 35 & 94 & $24 \cdot 4$ & 22 & $23 \cdot 4$ & \\
\hline 45 & 102 & 26.4 & 20 & $19 \cdot 6$ & $0 \cdot 13$ \\
\hline 55 & 108 & $28 \cdot 0$ & 36 & $33 \cdot 3$ & \\
\hline \multicolumn{6}{|l|}{ Education: } \\
\hline $0-6$ years & 251 & $66 \cdot 4$ & 75 & 29.9 & \\
\hline$\geqslant 7$ years & 127 & 33.6 & 22 & $17 \cdot 3$ & 0.01 \\
\hline \multicolumn{6}{|l|}{ Income: } \\
\hline $0-15000$ Swedish crowns & 185 & 49.9 & 55 & $29 \cdot 7$ & 0.07 \\
\hline$\geqslant 15100$ & 186 & $50 \cdot 1$ & 39 & $21 \cdot 0$ & \\
\hline \multicolumn{6}{|l|}{ Occupational status: } \\
\hline Manual workers & 293 & $75 \cdot 9$ & 86 & $29 \cdot 4$ & 0.002 \\
\hline Clerks & 93 & $24 \cdot 1$ & 12 & 12.9 & \\
\hline$\geqslant 6$ yes answers & 44 & $11 \cdot 4$ & 19 & $43 \cdot 2$ & \\
\hline \multicolumn{6}{|l|}{ Test "synonyms": } \\
\hline $0-18$ points & 182 & $49 \cdot 7$ & 57 & $31 \cdot 3$ & 0.01 \\
\hline$\geqslant 19$ points & 184 & $50 \cdot 3$ & 36 & 19.6 & \\
\hline \multicolumn{6}{|l|}{ "Instruction test": } \\
\hline $0-13$ points & 181 & 49.9 & 54 & $29 \cdot 8$ & 0.05 \\
\hline$\geqslant 14$ points & 182 & $50 \cdot 1$ & 37 & $20 \cdot 3$ & \\
\hline \multicolumn{6}{|l|}{ Test "arithmetics": } \\
\hline $0-27$ points & 180 & $48 \cdot 9$ & 57 & $31 \cdot 7$ & 0.008 \\
\hline$\geqslant 28$ points & 188 & $51 \cdot 1$ & 36 & $19 \cdot 1$ & \\
\hline
\end{tabular}

managers were all classified as clerks in the 1961 study.

STATISTICAL METHOD

In the univariate analyses variables with interval scales were dichotomised to fit fourfold tables.
Dichotomisation of earnings and correct answers in the three psychological tests was based on the median. The number of "yes" answers on the MarkeNyman scale of neuroticism was dichotomised at the 10 th decile.

The number of years of education was divided $\frac{7}{a} t$

Table 3 Prevalence of back abnormalities by sociodemographic and psychological variables

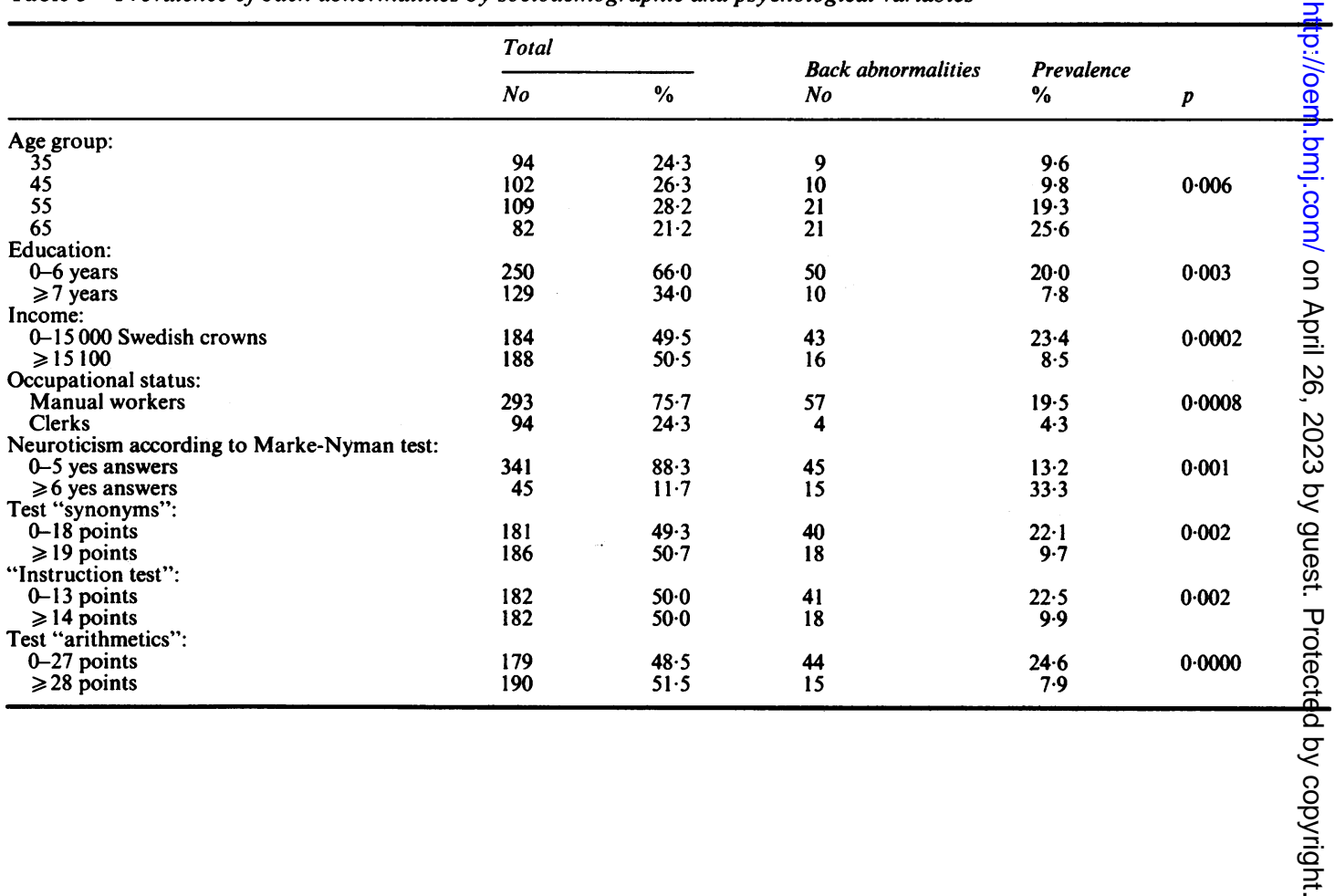


Clerks without back pain

Clerks with back pain

Manual workers without back pain

Manual workers with back pain

\section{Clerks with normal back}

Clerks with abnormal back

Manual workers with normal backs

Manual workers with abnormal backs

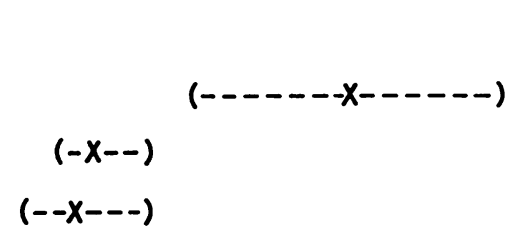

$(--x---)$ 


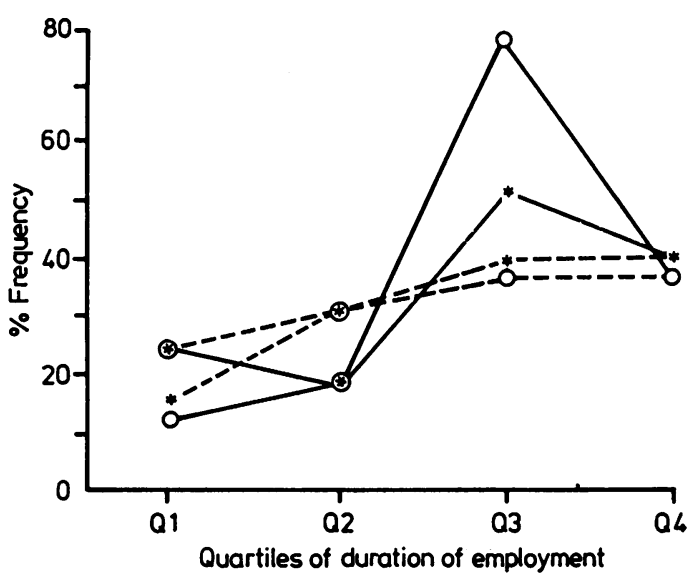

Fig 4 Back pain among manual workers in relation to duration of employment, heavy work, and frequent lifting: $\bigcirc-\bigcirc$ workers reporting their work as heavy, $\bigcirc---\bigcirc$ as not heavy, with *—_ frequent lifting at work, and with *---* no frequent lifting at work. Mean for duration of employment $16 \cdot 1$ years, $S D$ for duration of employment 12.9 years.

back pain on the one hand and heavy work or frequent lifting on the other.

Figure 5 shows the corresponding relation with back abnormalities. There is a significant increase in back abnormalities in manual workers with a duration of employment over the median ( $p=$ 0.0002 ) but there is no significant association with self rated heavy work or frequent lifting.

GENERAL HEALTH AND WORKING CAPACITY, SICK LEAVE, AND CHANGES IN WORKING CONDITIONS

The associations between back pain and back abnormalities and health and working capacity are shown in table 4. Highly significant associations between back pain and back abnormalities and doctors' and subjects' evaluations of poor health and reduced working capacity were shown. Both the strength of the association, as shown by the odds ratio, and the statistical significance are greater for back abnormalities than for back pain.

The odds ratio of having a change in working conditions on account of poor health or reduced working capacity is 3.7 for those with back pain compared with those without $(p=0.0001)$. The corresponding odds ratio with reference to back abnormalities is $5 \cdot 2$ $(\mathrm{p}=0)$.

Table 5 shows the associations between back pain and back abnormalities and sickness absence. There is a significant relation with an increase in the large number of days sick $(\mathrm{p}=0.006$ and 0.02 respectivel but not with the number of periods of absence ( $p \underset{\ominus}{\varnothing}$ 0.07 and 0.52 respectively).

\section{DIFFERENT SYMPTOMS AND RISK INDICATORS}

Table 6 shows the associations between back pain an back abnormalities and different symptoms and ris indicators. Pain in the chest or heart is associated wit back abnormalities $(\mathrm{p}=0.008)$ but not with back pain $(p=0.07)$. Associations were found between back pain and abnormalities and breathlessness whif going upstairs $(p=0.0005$ and 0.01$)$ and with headache $(p=0.007$ and 0.04$)$.

No association was found between back pain \&ิ back abnormalities and smoking $(p=0.15$ and $1 \boxplus$ respectively); teetotallers had a tendency towards les back pain than others but the difference is not significant $(p=0.06)$. No associations were foung between back pain or back abnormalities and bloo ${ }^{\mathrm{W}}$ pressure, serum cholesterol, urinary glucose, urinary protein, frequent coughing, or asthma (data not shown).

OTHER ANALYSES (data not shown)

Several work related psychosocial factors were als@ examined including work satisfaction, instrumentat attitude to work, experience of responsibility at work self assessed routine work, and hustling and nerve racking work. No statistically significant associations were found between any of these factors and eithe back pain or abnormalities and there was no assoc?

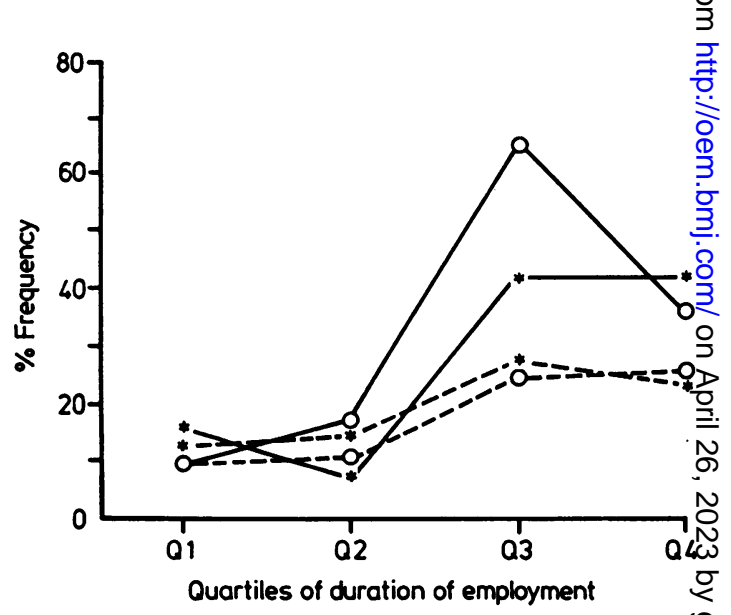

Fig 5 Back abnormalities among manual workers in relatio to duration of employment, heavy work, and frequent lifting: $\mathrm{O}-\mathrm{O}$ workers reporting their work as heavy, $\mathrm{O}---\mathrm{O}_{\square}$ as not heavy, with *- $*$ frequent lifting at work, and with *---* no frequent lifting at work. Mean for duration of employment $16 \cdot 1$ years, $S D$ for duration of employment 12.9 years. 
Medical, psychological, and social factors associated with back abnormalities and self reported back pain

Table 4 Association between back pain and back abnormalities and health and working capacity

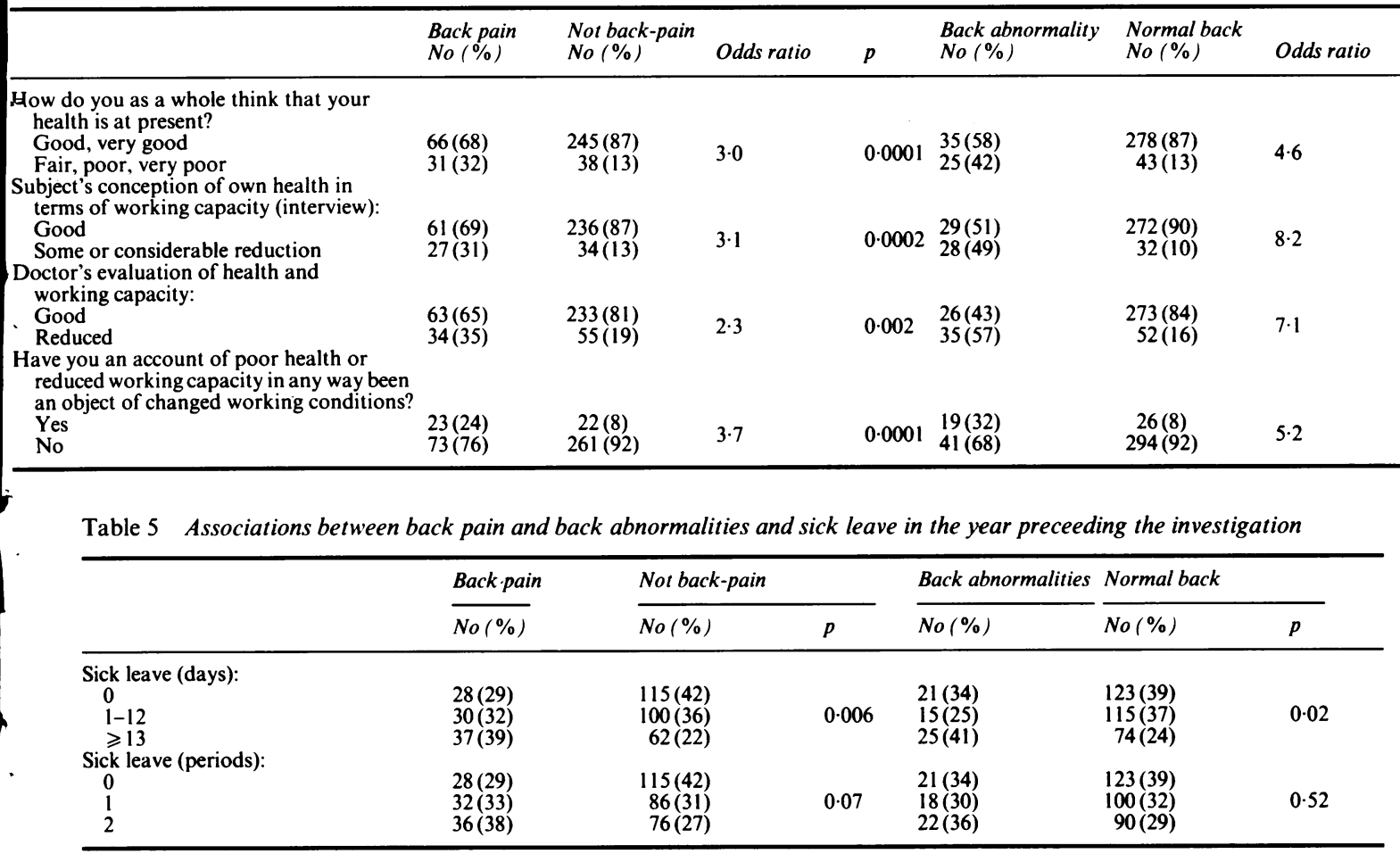

ation with shift work. Nor were significant associations found with several social contacts and leisure activity variables or with marital status.

\section{MULTIPLE LOGISTIC ANALYSES}

The following variables were used and tested in different combinations by multiple logistic regression for associations with back pain: neuroticism, duration of employment, age, heavy work, frequent lifting, use of alcohol, instruction test, test synonyms, and test arithmetic. Neuroticism and duration of employment showed significant direct associations with back pain (table 7).

A corresponding series of multiple logistic regression analyses was carried out using the same variables as above but exchanging abnormalities for pain; the results are shown in table 8 . Duration of employment, neuroticism, and test "synonyms" showed direct associations with back abnormalities. Age, which showed a significant association with back abnormalities in the univariate analysis, did not show any direct association.

Table 6 Associations between back pain and back abnormalities and different symptoms and risk indicators

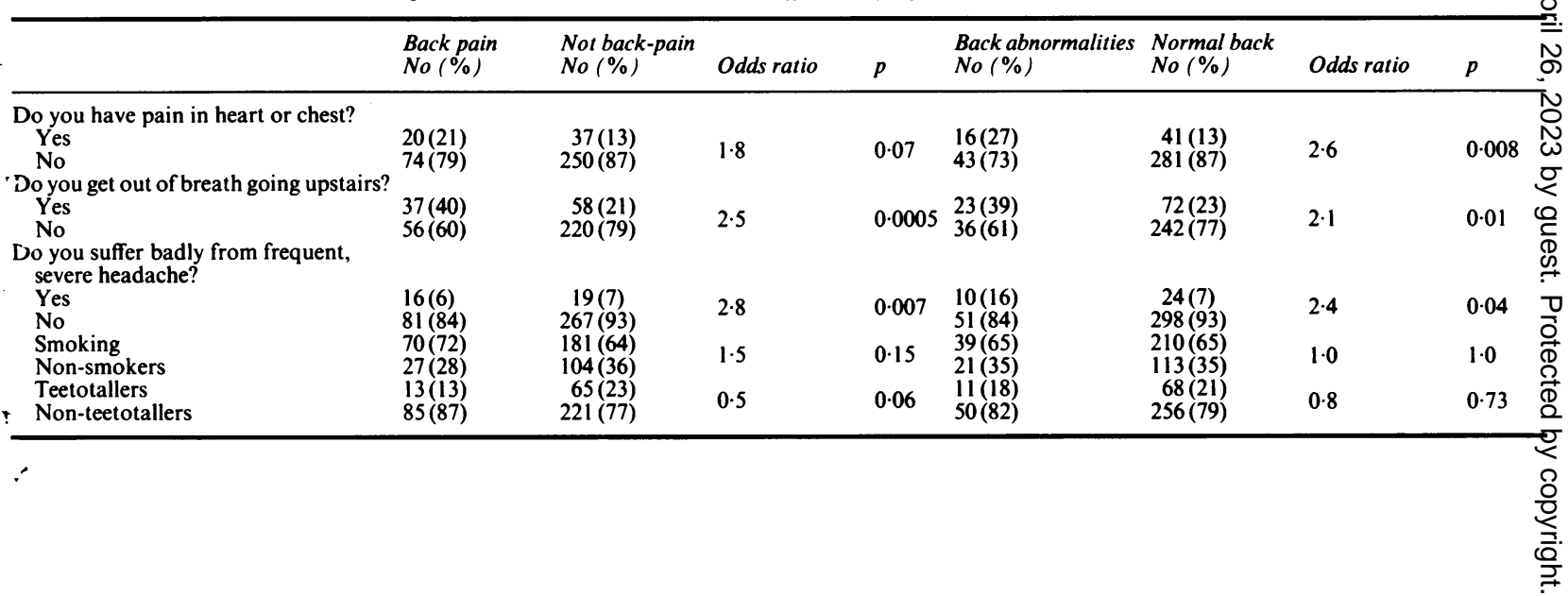


Table 7 Significant associations with back pain by means of multiple logistic regression analysis (manual workers)

\begin{tabular}{|c|c|c|c|c|}
\hline Variable & Coefficient & Standard error & $\begin{array}{l}\text { Odds ratio per } 10 \\
\text { variable units }\end{array}$ & $\begin{array}{l}95 \% \text { confidenes } \\
\text { interval }\end{array}$ \\
\hline $\begin{array}{l}\text { Neuroticism } \\
\text { Duration of employment }\end{array}$ & $\begin{array}{l}0 \cdot 101 \\
0.021\end{array}$ & $\begin{array}{l}0.034 \\
0.010\end{array}$ & $\begin{array}{l}2 \cdot 8^{*} \\
1 \cdot 2 \dagger\end{array}$ & $\begin{array}{l}1.4-5.4 \\
1.0-1.5\end{array}$ \\
\hline $\begin{array}{l}\text { *Units for neuroticism }= \\
\text { †Units for duration of em }\end{array}$ & $\begin{array}{l}\text { mean: } 2 \cdot 0 \mathrm{SD} \\
: 16 \cdot 1 \mathrm{SD}: 12\end{array}$ & & & จำ \\
\hline
\end{tabular}

\begin{tabular}{|c|c|c|c|c|}
\hline Variable & Coefficient & Standard error & $\begin{array}{l}\text { Odds ratio per } 10 \\
\text { variable units }\end{array}$ & $\begin{array}{l}95 \% \text { confidence } \\
\text { interval }\end{array}$ \\
\hline $\begin{array}{l}\text { Neuroticism } \\
\text { Duration of employment } \\
\text { Test "synonyms" }\end{array}$ & $\begin{array}{r}0.135 \\
0.029 \\
-0.047\end{array}$ & $\begin{array}{l}0.041 \\
0.012 \\
0.024\end{array}$ & $\begin{array}{l}3 \cdot 9^{*} \\
1 \cdot 3 t \\
1 \cdot 6 t\end{array}$ & $\begin{array}{l}1 \cdot 7-8 \cdot 5 \\
1 \cdot 1-1 \cdot 7 \\
1 \cdot 0-2 \cdot 6\end{array}$ \\
\hline
\end{tabular}

*Units for neuroticism = Number of yes answers; mean: 2.0 SD: 3.6.

+Units for duration of employment = Years; mean: 16.1 SD: 12.9.

+Units for test "synonyms" = Points; mean; 16.5 SD: 6.8.

\section{Discussion}

The examination carried out in 1961 was primarily designed as a broad study of the relations between work, age, and health and not especially aimed at back disorders. The breadth of the design, however, confers an advantage over investigations which look purely at the back and in which there is the potential risk that probands could be biased by adoption of statements of workload and other variables to factors regarding the back. 51215

The study population comprises a systematic, multimodally distributed sample, and is considered representative of all working men of the selected ages and worksites. The non-respondent group, $17 \cdot 5 \%$, was not analysed in 1961 and there are no data left to permit analysis now. It seems reasonable to assume that the non-respondents have a somewhat higher degree of sickness, disability, and negative social load as reported by Svensson ${ }^{5}$ and Westrin ${ }^{13}$ and that the prevalences found are slightly underestimated.

Back pain is frequently defined in studies as perceived back pain or low back pain - that is, pain in the lumbar region. In this study back pain refers to the thoracic as well as to the lumbar region but does not include the cervical region.

Hult reports that the incidence of thoracic back pain is $4-5 \%$ compared with $50-80 \%$ low back (lumbar) pain and that symptoms localised to the thoracic spine are "benign, only occasionally causing the patient to seek medical advice and rarely leading to incapacity for work." 1 Consequently materials regarding back pain and low back pain are sociomedically comparable.

The reliability of the question used to define a population with back pain has not been examined in this study but the reliability of questions elucidating an anytime incidence of low back pain ever is reported to be $84-92 \% .{ }^{28} 29$

A summing up evaluation of the physical examination of the back used as a central variable cannet be found. Westrin, ${ }^{13}$ Rowe, ${ }^{30}$ and Lloyd ang Troup ${ }^{31}$ used isolated signs and tests in the physical examination of the back in analyses of cross sectiong, retrospective, and prospective associations. Vällfows used the absence of objective findings by ba. patients for cross sectional analyses. ${ }^{32}$ The doctoofs evaluation of the back examination may possibly $\mathrm{Be}_{\mathrm{e}}$ influenced by his knowledge of anamnestic data. The results have to be read with this proviso.

The interobserver variation as regards back abnommalities has been analysed using manual workers at the three manufacturing worksites. Two docto jointly responsible for $80 \%$ of the total examinations, evaluated back abnormalities among manual workess at the same rate. The workers examined by the thirrd doctor were all employed at the smallest work sipe situated in a rural district and showed a significanty higher rate of back abnormalities. A further analys showed that the workers at this worksite had beon employed considerably longer than workers at the other sites: this could explain the interobserver difference, since duration of employment was shown to be associated with back abnormalities at each of the three manufacturing sites.

Reference figures for the prevalence of back paefin are given in the introduction and compare well widh the present figure of $25 \%$, which indicates that the expected group of back pain sufferers is detected with the method used. The proportion of backs evaluated as abnormal by physical examination was $16 \%$, dafa from the US Health and Nutrition Examination Service (HANES I) of 1971-5 shows a prevalence of $15 \%$ among adults aged $25-74 .^{33}$ 
Sixty six per cent of the group with back abnormalities reported frequent back pain. Since back pain is known to be episodic with free intervals ${ }^{31}$ and sometimes to disappear above the age of 50-55 owing to a presumed built in recovery mechanism, ${ }^{30}$ the remaining $34 \%$ could represent those with back disorders with long symptom free intervals, "recovered" back disorders, and perhaps a group with symptomless back disorders. It should be recalled that the high proportion of transfers and other changes in the working conditions may contribute to the absence of symptoms among the group of subjects with back abnormalities.

Forty two per cent of the sufferers from back pain had back abnormalities. The group with back pain and without back abnormalities presumably includes a subgroup that will later develop abnormalities and a subgroup that will never do so. It would be tempting to assume an association of neuroticism with the last group but, in fact, the association with neuroticism is stronger for back abnormalities than with pain. This contrasts sharply with the common view that neuroticism is associated with back pain, based on reports on patients with back pain ${ }^{18-20}$ and the results of Vällfors. ${ }^{32}$ She found a greater frequency of neurosis among back patients with no objective findings at examination. Her subjects were sick listed patients and the over-representation of neurosis among patients with no findings on back examination was calculated by reference to diagnoses on the Health Insurance registration cards. The association of neurosis with a lack of somatic signs may reflect the doctors' bias. In the present study working men were the subjects and neuroticism was measured on a scale.

The results of univariate analyses in the present study show that back pain and, more strongly, back abnormalities are associated with variables such as low income, low education, and occupational status. The association is strongest with the status of manual workers. The association of low education with back pain has been reported earlier by Nagi et al, ${ }^{6}$ and Cunningham and Kelsey ${ }^{33}$; Svensson, by contrast, found no such association. ${ }^{5}$ Differences in the prevalence of back pain between clerks and manual workers have been reported earlier by Nagi et al, ${ }^{6}$ but Partridge and Duthie found only slight or no differences ${ }^{34}$ and Rowe found none. ${ }^{30}$

Psychosocial work related factors did not show any significant association with back pain or back abnormality in this study, by contrast with the findings of Magora ${ }^{35}$ and Svensson, ${ }^{5}$ and this may provide additional evidence that it is the physical factors in the work environment that are the important determinants of back disorder.

The unusually pronounced difference between clerks and manual workers in this study as regards the prevalence of back pain and back abnormalities can probably be explained by the relative homogeneity of the two groups. The manufacturing works in the pulp and paper industry in 1961 were by and large classifiable as heavy industry. Men made up the clerks group and physically monotonous work such as typewriting was excluded, these tasks being almost exclusively performed by women. A register of clerks with back pain showed a pronounced predominance of foremen, who always start as manual workers, and other personnel who could be presumed to have "worked their way up from the floor."

This study shows that to a large extent the working conditions of back pain sufferers were changed because of their reduced working capacity. Westrin reported that probands more often reported a change of work than controls. ${ }^{13}$ In a retrospective study Kurinka and Nurminen reported that, compared with a reference group, iron ore workers with a disability pension gradually changed their work towards lighter tasks during the course of their working life. ${ }^{36}$ Such mechanisms of movement could explain the difficulty in demonstrating differences in the prevalence of back pain and back abnormality between groups with different workloads in a cross sectional study.

Magora has shown that the duration of employment is associated with back pain among groups with heavy work and that this association is stronger with groups characterised by an extremely heavy work load. ${ }^{9}$ In the present study there is a direct association between back pain and abnormalities and duration of employment but age was not directly associated with either. This confirms the results of Magora and indicates that heavy work in the long run gives rise to back disorders. ${ }^{9}$

The direct association of low results on the "synonyms" test with back abnormalities among the manual workers must be interpreted as representing an association of low education and social class with back disorder. Theoretically, this association could be explained by genetic factors or environmental factors acting in early life and leading to reduced physical resistance, or by the fact that less educated men get jobs with a heavier workload. The latter explanation appears the most plausible.

Both the subjects' and doctors' assessment of bad health and reduced working capacity showed strong associations with back pain and back abnormality, particularly the latter. Nagi described the relation between back pain and reduced working capacity and found that $38 \%$ of back pain sufferers had moderate or severe work limitations. ${ }^{6}$ This compares with $31 \%$ subject perception of reduced general working capacity and $35 \%$ for the corresponding medical evaluation in this study.

The present study presents an association between 
back abnormalities and pain in the heart or chest. Westrin found a corresponding association with low back pain, ${ }^{13}$ and Svensson an association between low back pain and suspected and definite angina pectoris. $^{5}$ No association with cardiovascular risk factors such as blood pressure or serum cholesterol concentration was found in the present study or by Svensson. It seems plausible to explain chest pain as a manifestation of musculoskeletal disorder or neuroticism, or both. The same factors could also explain the association between back pain and back abnormalities with headache found here.

Breathlessness on exertion was found to be associated with back pain and with back abnormality. This could be a non-significant effect of reduced physical working capacity caused by reduced exercise due to back disease. The finding may be compared with Svensson's report of a similar association and his report of diminished physical activity during leisure time among back pain sufferers. ${ }^{5}$

Since no evidence of an increased prevalence of other diseases or risk indicators among back pain sufferers or subjects with back abnormality was found, the association of back pain and back abnormalities with perceived health and long term working capacity and with the doctor's evaluation in the same area must be interpreted as direct. I conclude that back disorder as displayed by back pain or back abnormalities affects both general health and working capacity to a considerable degree.

Further analyses will focus on the predictive power of back pain and back abnormalities on overall elimination from the labour market during a 22 year follow up. The predictive power of neuroticism will also be analysed.

This work was supported by grant from the Swedish Environment Fund (ASF).

\section{References}

1 Hult L. Cervical, dorsal and lumbar spinal syndromes. A field investigation of a non-selected material of 1200 workers in different occupations with special reference to disc degeneration and so-called muscular rheumatism. Acta Orthop Scand 1954;suppl XVII.

2 Hult L. The Munkfors investigation. Acta Orthop Scand 1954;suppl XVI.

3 Valkenburg HA, Haanen HCM. The epidemiology of low back pain. In: Augustus A, White III, Stephen L, eds. Symposium on idiopathic low back pain, Miami, Florida 1980. Mosby Cy: Gozdon, 1982.

4 Biering-Sörensen F. A one-year prospective study of low back trouble in a general population. Dan Med Bull 1984;31:362-75.

5 Svensson HO. Low back pain in forty to forty seven year old men: a retrospective cross-sectional study. Gothenburg: University of Gothenburg, 1981. (Thesis.)

6 Nagi SZ, Riley LE, Newby LG. A social epidemiology of back pain in a general population. J Chronic Dis 1973;26:769-79.

7 Reisbord LS, Greenland S. Factors associated with self-reported back pain prevalence: a population-based study. J Chronic Dis 1985;38:691-702.
8 Ikata T. Statistical and dynamic studies of lesions due to ove $Z$ loading on the spine. Shikoku Acta Med 1965;40:262-86.

9 Magora A. Investigation of the relation between low back pain and occupation. Part II. Industrial Medicine 1970;39:504-10.:

10 Lawrence JS. Rheumatism in coal miners. III. Occupational factors. Br J Ind Med 1955;12:249-61.

11 Frymoyer JW, Pope MH, Costanza MC, et al. Epidemiologio studies of low-back pain. Spine 1980;5:419-23.

12 Magora A. Investigation of the relation between low-back pai and occupation. Part III. Physical requirements: sitting, stande ing and weight lifting. Industrial Medicine 1972;41:5-9.

13 Westrin CG. Low back sick-listing. Scand J Soc Med 1973? suppl 7.

14 Helander E. Back pain and work disability. Socialmedicinsk Tide skrift 1973;50:398-404. (In Swedish.)

15 Bergquist-Ullman M, Larsson U. Acute low back pain in indus try. Acta Orthop Scand 1977;suppl 170.

16 National Swedish Social Insurance Board. Early retirement pen sions granted in 1976. Stockholm: National Swedish Insurance Board, 1978.

17 Faxén N. Morbidity statistics on a material from a public healtbr insurance office. Nord Med 1959;23:638-41. (In Swedish.) w

18 Hanvik LJ. MMPI-profiles in patients with low-back pain. Jouß nal of Consulting Psychology 1951;15:350-3.

19 Leavitt SS, Johnston TL, Beyer RO. The process of recovery? Part 3. Mapping the health care process. Industrial Medicin $\vec{e}$ 1972;41:7-11.

20 Donovan W, Dwyer AP, White BWS, et al. A multidisciplina approach to chronic low-back pain in Western Australia. Spine 1981;6:591-7.

21 Abramson JH, Terespolsky L, Brook JG, et al. Cornell medicat index as a health measure in epidemiological studies. A test of the validity of a health questionnaire. Br J Prev Soc Med 1965 19:103-10.

22 Brodman K, Erdmann AJ, Wolff HG. Cornell medical index health questionnaire (manual). New York: Cornell Universito Medical College, 1956.

23 Nyman GE, Marke S. Medical questionnaire. Lund: Lunळ University, 1958. (In Swedish.)

24 Marke S, Nyman GE. Somatic and mental complaints in a youn population. Socialmedicinsk Tidskrift 1961;38:315-23. (In Swedish.)

25 Dureman I, Sälde H. Studies in psychometric and experiment $\overline{d P}$ methods for clinical evaluation of mental functioning. Stock holm: Almqvist \& Wiksell, 1959. (In Swedish.)

26 Helander J. On age and mental test behaviour. Acta Psychologic Gothenburgensia VII. Gothenburg: Almqvist \& Wiksell, 196꼭 (Dissertation.)

27 Dixon WJ, Brown MB, Engelman L, et al. BMDP statistică software. Berkeley: University of California Press, 1981.

28 Biering-Sörensen F, Hilden J. Reproducibility of the history of low-back trouble. Spine 1984;9:280-6.

29 Westrin CG. The reliability of autoanamnesis. Scand J Soc Med 1974;2:22-35.

30 Rowe ML. Low back pain in industry. J Occup Med 1969;1톨. 161-9.

31 Lloyd DCEF, Troup JDG. Recurrent back pain and its predico tion. J Soc Occup Med 1983;33:66-74.

32 Vällfors B. Acute, subacute and chronic low back pain. Clinical symptoms, absenteeism and working environment. Scand $\mathscr{\omega}$ Rehabil Med 1985;suppl 11:3-98.

33 Cunningham LS, Kelsey JL. Epidemiology of musculosceleta impairments and associated disability. American Journal of Public Health 1984;74:574-9.

34 Partridge REH, Duthie JJR. Rheumatism in dockers and civi T $^{+}$ servants. A comparison of heavy manual and sedentaryo workers. Ann Rheum Dis 1968;27:559-68.

35 Magora A. Investigation of the relation between low back pain and occupation. V. Psychological aspects. Scand J Rehab? Med 1973;5:191-6.

36 Kuorinka I, Nurminen M. Arduousness of work, career and diseability pensioning of Finnish iron ore miners. Scand J Soc Med 1984;12:69-74. 